\title{
Educating Adolescents in Life Skills for Achieving Sustainable Development in Nigeria
}

\author{
Mohammed Garba ${ }^{1}$, Azizatu Aliyu ${ }^{2}$, Abdu Alhaji Garba ${ }^{3}$, Surajo Muhammad ${ }^{4}$ \\ ${ }^{I}$ Department of Psychology, School of Education, Aminu Saleh College of Education, Azare, Bauchi State, Nigeria \\ ${ }^{2}$ School of Educational Services, Aminu Saleh College of Education, Azare, Bauchi State, Nigeria \\ ${ }^{3}$ Department of Educational Psychology, School of Education, Federal College of Education, Okene, Kogi State, Nigeria \\ ${ }^{4}$ Department of History, School of Arts and Social Sciences, Jigawa State College of Education, Gumel, Nigeria
}

\begin{abstract}
Education was recognized globally as the key to overall development. The understanding of the value of education in human life and with the change in policies of recruitment materialisms which demand employable youth especially in Nigeria, it become necessary to provide youth with life skills education. This disquisition focus on ways forward in educating adolescence on life skills for achieving sustainable development in Nigeria. Been adolescence are the most powerful, active, diligent, creative, contributive, innovative and energetic people. Life skills education is essential tool for empowering those adolescent to act responsible, increase civil capacity by enhancing and improving the workforce, social tolerance and less likely to resort to anti-social behaviour for achieving sustainable development. It is said to be recommended among others that government should provide adequate provision of social services that are beneficial to the poor masses, fostering economic growth, empowerment of youth to boast business in different dimension toward achieving sustainable development goals.
\end{abstract}

Keywords: Education, Adolescent, Life Skills, Sustainable Development

\section{INTRODUCTION}

$\mathrm{L}$ ife skills is a psychological competences and personal skills that help people to make carefully by decisions, communicate effectively and with others, develop coping skills with surrounding circumstances, and manage oneself that leads to progress and success of the society. Life skills are also the capabilities that enable individuals to take adaptive and positive behavior that makes them able to deal with the events and challenges of everyday life and to participate in the modern world full of new challenges and handle everything from interactions with others to identifying and processing emotions. This is done through the promotion of positive personal behaviors, social adaptation, citizenship and positive attitudes at work which only life skills education can provide.

The importance of having life skills education in adolescence life lies in their ability to adapt to all circumstances and succeed in the renaissance and prosperity of society. One of the most important problems that demand quick attention and solutions these days is the lack of life skills for the new generation. This is because there is a lack of life skills in the output of educational institutions. As a result, many fail in their careers and personal lives due to the absence of these skills they must have. Life skills education helps students build confidence in both communication and cooperative and collaborative skills, provide them with tools important for development, find new ways of thinking and problem-solving and provide methods on how to socialize, make new friends and recognize the impact of their actions and behaviors.

The Sustainable Development Goals (SDGs) defines the world we want. They apply to all nations and mean, quite simply, to ensure that no one is left behind. The Sustainable Development Goals (SDGs) were born at the United Nations Conference on Sustainable Development in Rio de Janeiro in 2012. The objective was to produce a set of universal goals that meet the urgent environmental, political and economic challenges facing our world. The SDGs replace the Millennium Development Goals (MDGs), which started a global effort in 2000 to tackle the indignity of poverty. The MDGs established measurable, universally-agreed objectives for tackling extreme poverty and hunger, preventing deadly diseases, and expanding primary education to all children, among other development priorities.

Through the pledge to Leave No One Behind, countries have committed to fast-track progress for those furthest behind first. That is why the SDGs are designed to bring the world to several life-changing 'zeros', including zero poverty, hunger, AIDS and discrimination against women and girls. Everyone is needed to reach these ambitious targets. The creativity, knowhow, technology and financial resources from all of society are necessary to achieve the SDGs in every context.

Sustainable Development Goals (SDGs) are the goals that take off from development goals (MDGs). The MDG were time-bounds goals agreed by world leaders at UN summit in September, 2000 on a deadline of 2015 with specific target on poverty alleviation, education, gender equality, child and mental health, environmental stability contributing to combat malaria and HIV/AIDs reduction all on a global partnership for development. With the transition to SDG as launched and approved by the world leaders at United Nations general assembly in September, 2015 the goals are: no poverty, zero hunger, good health and wellbeing, quality 
education, gender equality, cleaning and sanitation such education that can ensure intergenerational equity, poverty alleviation, environmental preservation and restoration, natural resources conservation and juts and peaceful society. The only agency that is fit and capable of supporting, assisting, guiding and taking up the functions of the youth and adolescent, preparing them for their future adult roles. Therefore, the adolescents need to be provided with not only the knowledge but also affordable and clean energy, decent world, empowerment skill acquisition that can make them suffer reliance for economic growth and development.

Nigeria is most popular nation in Africa. According to Nigeria National Bureau of Statistics estimated (2020), the population estimate Nigeria was $206,400,000$ and out of that number/population about $65 \%$ of those numbers are between the ages of $10-29$ years which consider as adolescent. John and Luke (1704) view adolescence as the period when a child grows into maturity. It's a period of human life generally characterized by enormous physiological and beavioural changes. Expectedly, adolescent serve as work force for any nation. The life of an adolescent depends on the support, assistance and guidance that he/she receives from the parent, teachers, peers and adult world.

To achieve a Sustainable Development Goals in Nigeria, education becomes life training in the art of putting an individual into action. UNESCO (2017) stated that, education for sustainable development aim at developing competencies that empower individual to reflect on their own action, taking into account their partially increased in civil capacity by enhancing and improving the workforce, social tolerance, environmental stewardship, participation in community-based decision making, and quality of life. Therefore, Nigerian adolescents need life skill education and should be part of their co-curricular activity toward achieving sustainable development goal in the country. The central focus of this paper is looking at the processes of educating adolescent in life skills for sustainable development in Nigeria.

\section{SUSTAINABLE DEVELOPMENT GOAL IN NIGERIA}

The sustainable development goals (SDGs) are built in addition to other goals of the eight millennium goals. The MDG were time bound goals agreed on by world leaders at a UN summit in September 2000 on a deadline 2015. With the transition to SDG as lunched and approved $b$ the world leaders at United Nations General Assembly in September, 2015 , the goals are; not poverty, zero hunger, good health and wellbeing, quality education, gender equality, clearing and sanitation, affordable and clean energy, decent work and economic growth.

The sustainable development goals (SDGs) have serious concern for education in Nigeria. The programme cares with the policy makers, administrators, teachers, parents and stakeholder. The overall goals for education and sustainable development in Nigeria as pit by Ikechukwu et'al
(2014), Itari and Ugbe (2018) in the work of Nasiru (2019) is the integration of the principles, value and practice of sustainable development into all aspects of education and learning. The authors posit the following objectives:

1. Facilitating, networking and collaboration among stakeholders in education for sustainable development.

2. Fostering greater quality of teaching and learning in education and sustainable development.

To achieve a sustainable development goal in Nigeria, it required quality education as an effective means to fight poverty, build democracies, and foster peaceful societies, self-reliance and empower individual, give them voice, unlock their potentials, open pathways to self-actualization and broadens perspectives to open minds to pluralist and effective leadership such are perceived as key strategies for actualizing sustainable development in the country. Considering the population in the country, the vision of achieving sustainable development is not possible without quality education that seek out the learner, acknowledges the learner's knowledge and experience, make content relevant, use many instructional and learning processes, enhance the learning environment, self-reliance, create a legislative framework and implements good policies (UNESCO, 2014).

Thus, quality education becomes necessary to be provided for Nigeria youth. Adebayo (2015) in the work of Ndubuisi (2018) describes a youth as a person between the age of 15 and 24 but Nigeria National Youth development policy classified all person aged $18-35$ years as adult and Nigerian as youth. The youth in Nigeria constitute the most essential part of population. They are the most powerful, active, diligent, creative, contributive, innovative and energetic people. The youth people, (adolescent) in Nigeria should be given universal access to high-quality education, access to decent work and livelihood as well as policies that empower adolescent and youth to experience a good living, so that they can prove be productive and constructive in any field of life that lead to achieving sustainable development in the country.

\section{ADOLESCENT AS PATH FOR ACHIEVING SUSTAINABLE DEVELOPMENT}

Adolescent means "to grow up" that is leaving all that is childlike to develops new personality behaviour and attributes to deal effectively with ones roles as an adult. John (2015), asserts the adolescent is inherently a time of "storm and stress" when all young people go through some degree of an emotional and behavioural up-heaved before establishing a more stable equilibrium in adulthood. The transition is complex as it is not only external but internal as well. Due to its complex nature, adolescence manifests some unique characteristics, which make this stage very vital for adolescence life. These characteristics are as follows:

- Physical and physiological changes 
- Cognitive changes

- Social changes

- Emotional changes

- Moral changes

- Academic changes

It is clear that in each aspect there is a tendency of this chart to move to the extreme. It is a period of capacity building and one of increase vulnerability and risk Charhan (1987). It is often during this vulnerable period in life when poverty extends from one generation to the next, which results to adolescents dropping out of school and pushing them into the labour market.

On the SDGs, member states agreed to include adolescent (youth) development related targets under many of the 17 sustainable development goals. To achieve sustainable development goal in Nigeria, investment in adolescent are crucial to grow their economics and reap demographic dividends, build institutional capacity, strengthen human capital expanding environmental opportunities and gender equality and empowering girl and women to achieving economic empowerment and independence across all levels. Also a focus on transferable skill (such as problem-solving, communication, creativity and leadership) will help the youth to adapt to labour market changes, including new technologies as well as assist young people in the informal sectors to become successful entrepreneurs (UNICEF, 2016). More so, Nigeria youth and adolescent should be provided with quality education for sustainable development such empowers them to take information decision and responsible action for environmental integrity.

\section{NEED FOR LIE SKILLS EDUCATION FOR NIGERIA ADOLESCENT}

Adolescent required a combination of cognitive and social skills to tackle their problem, and prepare for future challenges. Adolescent period as it a significant state of growth and development, marks the period of transition from childhood to adulthood. It is characterized by rapid psychological changes and psychological maturation. It is also a stage when youth people extend their relationship between beyond parents and family as the period mark with cognitive changes, the adolescent mental process becomes more analytical and capable of abstract thinking, better articulation, more creative, idealism and risk taking and taking uniformed decision on crucial issues. Gerima (2010), come up with some key issues and concern observed among adolescent include those relating to forming a self-image, managing emotion, building relationships, strengthening social skills, and dealing with or resisting peer pressure and are more prone and vulnerable to high risk situation and may easily succumb to it how well an adolescent deals with these challenges is decided by a host of factors that include their personality, psychosocial support from the parents, teachers and peers, and the life skill that they posses. Herein, adolescent are considered to be the most dynamic and productive members of the society, as a results of their physical and intellectual capacity.

Bonnie (2014) stated that, without competency in life skill education, the adolescent will become lost because of the inevitable tension created by globalization, such as the conflict between global and local, universal and individual, tradition and modernity, short term and long term considerations, excellences and equality opportunity, knowledge expansion and knowledge assimilation spiritual and material, beside the increasing divide between the rich and poor. Therefore, there is a need to provide adolescents with life skills knowledge as well as opportunities to practice life skills education are understood to be the essential tools for empowering an adolescent or youth to act responsible, take initiative and able to rise above emotional impasses arising from daily conflicts, entangled relationship and peer pressure, they are less likely to result to anti-social behaviour. In the work of Bonnie (2014) view that UNESCO, UNICEF and WHO have listed ten care life skills. These include:

1. Self-awareness

2. Empathy

3. Critical thinking

4. Creative thinking

5. Problem solving

6. Decision making

7. Communication skills

8. Interpersonal skills

9. Coping with stress

10. Coping with emotion

Therefore, Nigerian adolescents need life skill education that will help them adopt to changes over a lifetime and abilities for adaptive and positive behavioural that enable individual to deal effectively with the demand, challenges and stress of everyday. They need skills in each of the poor pillars of education for all-alarming to know, learning to do, learning to live together and with others, and learning to be UNESCO (2014).

The Nigerian day adolescent get into life threatening problems and take extreme steps such as violent acts, suicides, substance, drugs and alcoholism. Unprepared adolescent become so aggravate when they step into the real-life. There is an increase in the number of violence, political crisis, kidnapping, cultism, and young wastage. Nigeria adolescent needs to be prepared at a very young stage with life skill education in-term of entrepreneurial and attributes. They have to be taught to imbibe life skill of problem-solving, decision making, self-awareness, critical thinking, interest and career option, adaptive and positive behaviour that enable the youth or adolescent to effectively deal with demand and challenges of everyday life, looking forward even in difficult situation to find solution that can help to end poverty in all its forms, end hunger, promote lifelong learning opportunities for all, promote and sustained inclusive and sustainable economic growth, take urgent action to combat climate change and its 
impact, ensure healthy live and promote well-being for all at all ages, productive employment and decent work for all for achieving sustainable development in the country.

\section{CHALLENGES OF SUSTAINABLE DEVELOPMENT GOALS IN NIGERIA'S EDUCATIONAL SECTOR}

Education is a light that shows the human being the right direction to surge. Education aimed at developing skills, abilities, understandings and knowledge in individuals so that one can contribute his or her quota in national development. It is through the provision of quality education that the sustainable development goals (SDGs) can be achieved. All the variables responsible for given vibrant education should be well available and utilize in the best form. Therefore, Nigeria to attain sustainable development through education all hand must be put on a deck. The actualization of this goal in Nigeria is however faced by the following challenges:

1. Poor Funding: Nigerians are very much aware that teacher education is bedeviled by poor funding from all levels of government. This has resulted in the inadequate provision of teaching and learning materials, dilapidated school building, overcrowded classes, lack of financial resources to carry out and plan sustainable development has a negative impact on Nigeria's educational sector.

2. Corruption: The United Nation Global Programme against corruption, UNGPAC (2012) define it as abuse of power for private gain. Foreign grants are needed as counterparts funding for the making real and revitalization of Nigeria's education sector at all level. However, due to weakness of social and governmental enforcement mechanism, absence of a strong sense of national community, poor pay incentives as seen as the major impediments to the economic development of the nation and significantly slow down NGO processes toward achieving sustainable development goals (SDGs) in Nigeria.

3. Lack of Focused Leadership: Change happens when there is political will. Change in government affect educational sectors negatively especially in Nigeria. Most of our political leader at all level considered educational sector as a consumable sector, that is why they handle the sector with less committed. If political leaders committed to the SDGs because they can see the benefits than we might see good result. The role of government officials would be to encourage political leaders to frequently monitor and exchange lesson on policies to achieve the SDGs.

4. Lack of a Database: Gathering detailed data is like most important tool for policy makers to assess their residents' needs, decision making, planning and target their policies accordingly. Nigeria lacks essential up-to-date information on characteristics of their school, location, staff strength, availability of classes, the state of their infrastructure. Without this information, how can official will make a plan and update on the progress on goal 4 ? This can hinder the achievement of SDGs in Nigeria.

5. Problem of Poor Quality Education: The problem of poor access to quality education by Nigerian children may hinder their ambition to achieve meaningful lifestyle and wellbeing. Consequently, to prevent the country from participating in the current global drive to achieve the Sustainable Development Goals. Verspoor (2008) in the work of Aboluwodi (2018), uses Cameroon, Kenya and Niger to illustrate his point while explaining the problem of poor access to education in Africa and no children from poorest income quintile in these countries, are enrolled in tertiary institution.

\section{CONCLUSION AND THE WAY FORWARD}

Academic excellent cannot yield success and happiness of adolescent in this era of global change. A productive healthy adult capable of living to their full potential are the bedrock of development. In order to ensure that Nigeria adolescents are capable of facing the challenges of $21^{\text {st }}$ century. Here is a need for them to be taught the life skill education. The youth should be active, diligent, entrepreneur, participate in decision-making and constructive in any field of life endeavor are the essential stepping-stone for developing from childhood to adulthood that lead to achieving of sustainable development goal in Nigeria.

Life skill education equips the adolescence with necessary intellectual capacity, skills that can help toward constructively with decision about life, ability to analyze information and experience in an objective manner. It enables an adolescence to be pool of potential entrepreneurs who are well equipped with skill and technical knowhow to set up and manage small or medium scale industries will be establish. This will enhance job economic social and practical development in Nigerian economic growth that can gear toward achieving sustainable development goals (SDGs).

To meet the SDGs agenda 4, Nigeria should do more to promote education. If our government is serious and committed towards the development of a nation; the total percentage of budgetary allocation to education should be adequately funded as it was agree and describe in UNESCO. Also communities should look for an alternative source of funding it could be through levying members, group to wealthy individual and corporate bodies.

\section{RECOMMENDATION}

- The federal, state and local government should provide adequate provision of social services that are beneficial to the poor masses, fostering economic growth to boast businesses in different dimension.

- Government must provide effective intervention that help achieve outcome on a number of fronts, such as those focusing on adolescent and youth inclusion. 
- The federal, state and local government must provide specific spaces for national dialogue, consultation and social media campaign, reaching out to those marginalized, and promoting young people role as agents to change.

- Government must provide programme that contribute to the protection, health and development of young women and men and girls and boys, and realize the rights and needs of the hardest-to-reach adolescents and youth, in particular adolescent girls.

- There are a need for public awareness on the Sustainable Development Goal through translation of the SDGs into different Nigeria language and interpreting them in the curriculum.

- Adequate funding of the system holds the key to effective implementation of stated goals.

- Nigerian government should comply with the UNESCO declaration of $26 \%$ budgetary allocation for the development of educational system.

\section{REFERENCES}

[1]. Aboluwodi, A. and Owolewa, O. O (2018). Repositioning Education to Achieve Sustainable Development Goal in Nigeria. International Journal of Advance Research in Public, Social Development and Enterprise Studies. 3(1): 68 - 76.

[2]. Bonnie, A. C and Neeta (2014). Educating Adolescents in Life Skills for Human Resource Development in India. International Journal of Education and Humanities. 1(2): 36 - 42.
[3]. Federal Bureau of Statics (2020). Nigeria Population. National Bureau of Statistics Bulletin, 2020.

[4]. Garima, S. (2015). The Importance of Life Skills for Adolescents. Retrieved from https://www.whiteswanfoundation.org/lifestages/adolescence/the-importance-of-teaching-your-adolescentlife-skill . Accessed 02/12/2020.

[5]. John and Locke (1632-1704). Historical Views of Child and Adolescent Development. Retrieved from https://courses.lumenlearning.com/atd-fscjchildpsychology/chapter/historical-views-of-child-and-adolescentdevelopment/ on 03/12/2020.

[6]. Nasiru, G. (2019). Education and Sustainable Development in Nigeria: Issues, Challenges and the Way Forward. Paper Presented at National Conference, School of Arts and Social Sciences, Aminu Saleh College of Education, Azare.

[7]. Ndubuisi, O. P. and Anekwe, R. I (2018). Strategies for Achieving Sustainable Development in Nigeria: The Nexus. International Journal of Academic Research in Business and Social Sciences. 6(8): $168-180$.

[8]. NIT (2018). Sustainable Development Project Workshop Manual for Primary School Teachers, First Edition, NTA Publishers.

[9]. The United Nations Global Programme against Corruption (UNGPAC, 2012). UN Decade of Education for Sustainable Development $(2005$ - 2014).

https://leading_the_international_agenda/education_for_sustainabl e_development. Accessed $14^{\text {th }}$ November, 2020.

[10]. UNDP (2017). Working with Adolescents and Youth to Achieve the Sustainable Development Goals.

[11]. UNESCO (2014). Contributing to a more Sustainable Feature: Quality Education, Life Skills and Education for Sustainable Development. 